\title{
PROHIBICIÓN DE REGRESO ${ }^{-{ }^{-}}{ }^{2}$
}

\author{
Ignacio Ananias Zaror \\ $<<$ No todo es asunto de todos $>>$ \\ G. Jakobs
}

1. Fundamentos; 2. La probibición de regreso, ilimite a la posibilidad de sancionar como partícipe imprudente o a la autoría de un delito culposo?; 3. Delimitación de la esfera de aplicación de la teoría; 4. Probibición de regreso: ¿una limitación normativa a la responsabilidad penal accesoria en la inducción?; 5. Casos en que es necesario impedir sucesivas responsabilidades "bacia atrás"; 6. Probibición de regreso y teoría del bien jurídico; 7. Principio de confianza; 8. Sintesis; Bibliografía.

¿En qué casos es factible para un individuo apartarse de un hecho en el que ha contribuido?

A modo de prolegómeno, consideramos sumamente ilustrativo el fallo del Tribunal Supremo del Reich ${ }^{3-4}$ en el cual se condenó como autora de homicidio imprudente a una mujer que provee a su amante de veneno, quien dolosamente lo utiliza para matar a su esposa. Si bien es diáfano que la acción de la mujer puede llegar a ser punible a través de la figura de expendio -a cualquier título- de sustancias peligrosas para la salud, regulada en los artículos 314 y 317 del Código Penal chileno ${ }^{5}$, así como que el marido debe ser condenado como autor de homicidio doloso, es a lo menos cuestionable la solución brindada por el T.S. en cuanto a la calificación de la conducta de la amante. Ello por dos razones

\footnotetext{
1 Texto escrito para la cátedra "Problemas generales de la Parte Especial del Derecho Penal" del profesor Antonio Bascuñán Rodríguez en la Facultad de Derecho de la Universidad de Chile (2009).

${ }^{2}$ La tradicional traducción a la lengua española de RegreBverbot es "prohibición de regreso", empero perviven opiniones discrepantes que señalan que su más idónea conversión sería la de "prohibición de retroceso", para evitar así una especie de oxímoron, "en la medida en que «regresar» expresa la idea de un punto de partida (fundamentador de la imputación) y la «prohibición» sería sólo una forma de restringir tal imputación ya fundamentada, mientras que lo que se cuestiona en estos casos es precisamente si las conductas de terceros que intervienen con anterioridad al ejecutor inmediato son candidatas a una imputación en coautoría o participación, esto es, se discute la posibilidad («prohibición») de «retroceder» (fundamentar la imputación) hasta la responsabilidad de un sujeto que intervino con anterioridad" [obtenida en] Frisch, Wolfgang: "La imputación objetiva: estado de la cuestión", en "Sobre el estado de la teoría del delito" (Seminario de la Universitat Pompeu Fabra), $1^{\text {a }}$ edición, Civitas Ediciones, Madrid, N. del T. (Ricardo Robles Planas), en la nota al pie $(\square \cdot), 2000$, p. 28.

* Estudiante de pregrado de la Facultad de Derecho de la Universidad de Chile.

${ }^{3}$ De ahora en adelante T.S.

${ }^{4}$ Publicada en: RGSt, t. 64, p. 370.

${ }^{5}$ De ahora en adelante C.P.Ch.
} 
fundamentales: (1) el que ayuda a alter para que mate a ego, no comete el delito de homicidio, y (2) no toda posibilitación culposa de un hecho doloso es punible.

La teoría de la prohibición de regreso, junto a criterios como el del incremento de riesgo, el principio de autorresponsabilidad y el principio de confianza, entre otros, pertenece a un grupo de medios a través de los cuales se busca eludir la imputación (limitar el castigo).

\section{Fundamentos}

Se han aducido diversas proposiciones teóricas para argumentar lo imperativo de la aplicación de ésta. Para su más acertada comprensión aglutinaremos las cardinales, atendiendo al tratamiento dogmático ofertado para limitar la aplicación del ius puniendi.

(a) Teoría tradicional de la prohibición de regreso (Frank): Esta nomenclatura, así como su inicial fundamentación es atribuible a Frank, quien en el ámbito de la causalidad sostiene la impunidad de todo a quien favorezca imprudentemente una conducta dolosa o culpable. Para él no pueden ser consideradas causas del resultado las condiciones de una posterior obtención del resultado, de forma libre y consciente por otro individuo que se sirve de aquellas condiciones primitivas (es decir, las aportaciones anteriores a una intervención dolosa y culpable -causa liberason penalmente inocuas ya que hacia atrás de aquéllas opera una prohibición de regreso). Para el autor, la causalidad "promovida psicológicamente" no puede fundamentar la responsabilidad.

"La debilidad de esta tesis la pone de manifiesto su propio autor al tener que excepcionarla para los supuestos de inducción y autoría mediata". Así también el hecho de que Frank no descartaba la posibilidad de sanción del "hombre de atrás" a título de participación. Por tanto, para Frank esta teoría se constituye como un límite a la responsabilidad por autoría, trazando la frontera entre intervención punible o impune en el delito, para la participación imprudente, no la prohibición de regreso, sino que los requisitos que la ley penal establezca para la participación en sî (por lo que deviene en insuficiente).

No obstante lo precedente, actualmente se ha visto refrendada la teoría de Frank por autores como Hruschka. Para este último, también la prohibición de regreso presupone una acción que permita tildarse como libre. Mas, según él (siguiendo a Platner), la libertad "se halla en contraposición a la necesidad de la

\footnotetext{
${ }^{6}$ Martínez Escamilla, Margarita: La imputación objetiva del resultado, 1ª edición, Edersa Editoriales, Madrid, 1992, p. 348.

7 [así también] Robles Planas, Ricardo: La participación en el delito: fundamentos y límites, Editorial Marcial Pons, Madrid, 2003, p. 84.
} 
naturaleza"8 (movimientos físicos necesarios). Lo anterior deriva en que si se observa un proceso como una acción física necesaria, se debe considerar como un efecto de la causa que lo produce. En oposición a ello, una acción libre se debe calificar como el nuevo comienzo de una cadena de causas (independiente de las condiciones iniciales preexistentes).

Para Hruschka, "imputar significa considerar un proceso como acción libre" ${ }^{\text {"10 }}$, por lo que si un sujeto que actúa de manera libre ejecuta una acción típica, se le califica de autor, no aportando todos quienes se encuentren cronológicamente detrás de éste causa alguna que ocasione la acción libre, fundamentando así conceptos tales como el de inducción. Lo precedente es consecuencia directa de que la acción del autor no es el efecto de una causa (en términos de Kant y Mill), ya que la acción del inductor no determina el hecho del inducido, por lo que aquél no causa el hecho de éste. ${ }^{11}$

(b) Puntos de vista político-criminales que abogan a favor de la prohibición de regreso: Se reclama la innecesariedad de castigo del partícipe imprudente cuando la producción del resultado es retribuida a su autor doloso, ya que "la seguridad jurídica se ve satisfecha si puede hacerse responsable al segundo actuante, que ha ejecutado el hecho dolosamente"12, ya que según Naucke ${ }^{13}$, el comportamiento del primer individuo está tan distanciado del resultado final lesivo, que ninguna persona puede representarse que se encuentre prohibido. Es decir, al responder el autor doloso (evidentemente sólo de su hecho) opera una causa de exclusión respecto del aportante inicial imprudente, rigiendo, como Jakobs señala, "un estricto principio de absorción respecto de autores diferentes". ${ }^{14}$

\footnotetext{
8 Hruschka, Joachim: "Prohibición de regreso y concepto de inducción. Consecuencias", en Imputación y Derecho Penal. Estudios sobre la teoría de la imputación, Editorial Aranzadi S.A., Universidad de Navarra, 2005, p. 171.

9 "Moral" en lenguaje hegeliano. Entiéndase por libre aquella acción que no es consecuencia de una necesidad o una ignorancia (Pufendorf).

${ }^{10}$ Hruschka, Joachim: "Prohibición..." (nota 8), p. 174.

11 Ello porque Hruschka entiende como causa la última acción humana libre que desencadena el efecto (concepto opuesto al de la teoría de la equivalencia de las condiciones). A su vez, esta falta de equivalencia en los aportes de ambos determina para él la naturaleza accesoria de la inducción y ratifica, asimismo, la vigencia del concepto restrictivo de autor.

12 A una similar solución llega Wehrle, para el cual en los delitos dolosos siempre existe una prohibición de regreso sobre conductas previas imprudentes atendiendo al mayor desvalor de la intromisión dolosa en el delito doloso frente a la conducta culposa, debiendo permanecer esta "impune producto de la menor necesidad de pena de los hechos imprudentes" [analizado en:] Robles, Ricardo: La participación en el delito... (nota 7), p. 87.

13 Naucke, Wolfgang: "Sobre la prohibición de regreso en Derecho Penal", en Naucke, Otto y otros: La probibición de regreso en Derecho Penal, Universidad Externado de Colombia, Colección de Estudios No 11, 1998, p. 43.

${ }^{14}$ Jakobs, Günther: Fundamentos del Derecho Penal, $1^{a}$ edición, Editorial Ad Hoc S.R.L., Buenos Aires, 1996, p. 135.
} 
A su vez, se alude al cercenamiento de la libertad de actuación del ciudadano que provocaría esta "extensión insoportable" del Derecho Penal ${ }^{15}$ (punibilidad del partícipe imprudente). Asimismo, se aduce la "importancia para las dimensiones de las actividades investigadoras de la policía y de la fiscalía" ", como también la ineficacia preventiva (según criterios generales y especiales) de la punición de quien sólo aporta una condición al hecho punible.

Adherimos a Feijoo $^{17}$ en su acertada crítica a la postura de Naucke sobre la carencia de objeto desde el punto de vista de la prevención general, ya que esa idea "puede ser aplicada a todos los supuestos de participación, también a los dolosos" ${ }^{18}$ En atención a lo señalado, concordamos en que para Naucke las penas en los delitos imprudentes, más que retribuir culpabilidad, rellenan lagunas de punibilidad, lo que es totalmente inadmisible (!).

Asimismo, Naucke fundamenta la imposibilidad material de llevar a cabo las prácticas punitivas sin una prohibición de regreso ya que, como él señala, "conforme al tipo objetivo, en la mayoría de estos casos hay personas que han puesto una condición que no puede ser eliminada mentalmente sin que desaparezca el homicidio"19. Si bien concordamos con el fondo de su argumentación, nos parece que ésta, en cuanto a las razones en que la fundamenta, es no solamente errada, sino también incoherente desde un punto de vista sistemático. La primera afirmación se deriva de que no es relevante el vínculo causal, ya que en la prohibición de regreso éste siempre se admite, mas se debe determinar si al que aporta determinada condición puede o no imputársele el resultado sobrevenido. A su vez, porque la causalidad es un criterio de imputación necesario -aunque no suficiente- en el ámbito de los delitos de resultado. Por tanto, es totalmente errado afirmar que "si alguien utiliza dolosa o culposamente la situación creada por la acción de otro, para acarrear un resultado penal, la acción del primero es concausal para el resultado acarreado por el segundo; mediante la intervención del segundo, el nexo causal entre la acción del primero y el resultado posterior, no solamente no es 'interrumpido' [...], sino precisamente intermediado" 20 ; es decir que en el caso de un cazador que cuelga su escopeta cargada en el salón de una hostería y luego se produce una gresca donde alter mata a tiros con la escopeta del cazador a ego, por el hecho de colgar la escopeta, el cazador es causa de la muerte de ego, siendo para esta teoría el cazador autor de homicidio imprudente y alter autor de homicidio doloso ${ }^{21}$ (ello porque toda

\footnotetext{
15 [así] Reyes Alvarado, Yesid: Imputación objetiva, Editorial Temis S.A., Colombia, 1994, p. 332; y Naucke, Wolfgang: Sobre la probibición... (nota 13), p. 42.

${ }^{16}$ Naucke, Wolfgang: Sobre la probibición... (nota 13), p. 45.

${ }^{17}$ Feijoo Sánchez, Bernardo: Imputación Objetiva en Derecho Penal, Editorial Jurídica Grijley, E. I. R. L., Perú, 2002, p. 360.

18 Jakobs, Günther. [citado por] Feijoo Sánchez, Bernardo: Imputación Objetiva... (nota17), p. 359.

${ }_{19}$ Naucke, Wolfgang: Sobre la probibición... (nota 13), p. 42.

20 Welsen, Hans: Derecho Penal Parte General, Roque de Palma, Editor, Buenos Aires, 1956, p. 50.

21 Si bien puede que en el caso en cuestión concordemos con la punibilidad del cazador, no estamos conformes con el razonamiento que derivó en ella.
} 
conducta culpable que causa un resultado lesivo de modo evitable, aun cuando se vea intervenida por otro, acarrea responsabilidad producto de la equivalencia de causas).

Nos parece a su vez incoherente ya que, como él señala: "fracasan todos los argumentos dogmáticos que la doctrina [...] aduce apoyándose en la teoría de la equivalencia de las condiciones en contra de la prohibición de regreso". ${ }^{22}$ Por tanto, según la aseveración señalada, carece de sentido que, ante la ausencia de la segunda vuelva a imperar la primera, ya que existen otras soluciones más razonables mediante las cuales podría "superarse" aquello (v.gr. los criterios generales de la imputación objetiva).

Por tanto, como primera conclusión, nos parece correcta la afirmación de Jakobs en cuanto a que "la causalidad es sólo el mínimo de la imputación objetiva del resultado, pero debe ser completada con la relevancia jurídica de la relación causal entre acción y resultado"23 (tal como lo había afirmado ya el neokantismo). Una de las instituciones con las que Jakobs regula esta relevancia es la prohibición de regreso. ${ }^{24}$

(c) Conducibilidad del suceso (Otto): para esta teoría "es irrelevante si una persona ha puesto cualquier condición que no pueda ser suprimida mentalmente sin que desaparezca un resultado determinado con probabilidad lindante en la seguridad" 25 , ya que la conducibilidad reconoce su límite cuando personas que conocen de la situación riesgosa creada excluyen a quien imprudentemente ha abierto la posibilidad de una comisión dolosa del dominio del hecho, o crean con su actuación un nuevo peligro para la víctima (aplicando, como ya lo había establecido Maurach, un "proceso mental hipotético"). Es decir, el primero pierde la "posibilidad del dominio del hecho". Así, en el caso de la mujer que le proporciona veneno a su amante, ésta no responde penalmente por ausencia de dominabilidad.

Esta teoría es desmontable por distintas razones. Nos parece que la principal es la imprecisión de sus $\operatorname{conceptos}^{26}$, lo que puede derivar en serios

\footnotetext{
22 Naucke, Wolfgang: Sobre la probibición... (nota 13), p. 27.

23 Zaffaroni, Eugenio: Derecho Penal Parte General, 2a edición, Editorial Ediar, Buenos Aires, 2002, p. 515.

${ }^{24}$ Las otras son: riesgo permitido, principio de confianza y autopuestas en peligro.

25 Otto, Harro: "Diagnosis causal e imputación objetiva", en Naucke, Wolfgang: Sobre la probibición... (nota 13), p. 70.

${ }^{26}$ [así también] Roxin, Claus: Derecho Penal Parte General, Tomo I: Fundamento de la teoría del delito, $2^{\mathrm{a}}$ edición, Editorial Civitas, Madrid, 1996, p. 245, y Kindhäuser, Urs [en] "Seminario Estado de la teoría del delito, con especial referencia a la autoría y la participación”, 30 de Sept. al 01 Oct. de 2009, Facultad Derecho, U. Chile. Para este último, el quantum de la intervención es lo decisivo para la valoración cualitativa de la intervención. [Así también en] Kindhäuser, Urs: "Cuestiones fundamentales de la coautoría”, en Revista Penal, 2003 [disponible en:] www.cienciaspenales.net, p. 56.
} 
problemas de arbitrariedad en la imputación. También, porque si bien en el caso ya señalado de la amante llegaría a una solución acertada, en el ejemplo de la taberna aludido anteriormente dejaría impune al cazador, donde incluso, un radical como Jakobs $^{27}$, [atendiendo a las circunstancias] calificaría la conducta de éste como punible $^{28}$. Po último, porque "el dominio de un hecho doloso ajeno es en principio totalmente posible",29, por lo que no se puede excluir de manera omnímoda que el resultado antijurídico se impute tanto al autor doloso como al "hombre de atrás" (autoría mediata).

(d) Imputación por quebrantamiento de un rol (Jakobs): este autor construye una teoría de la prohibición de regreso genuinamente normativa ${ }^{30}$, es decir, desligada de aspectos naturalísticos. Para él, "quien realiza actos ejecutivos no sólo ejecuta su propio hecho, sino el hecho de todos, en cuyo caso la ejecución es al mismo tiempo su propio injusto y también el injusto de cada uno de los participantes"31 (mas respondiendo cada uno de su propio injusto). Es menester precisar que para Jakobs la comisión del injusto es propia cuando exista una razón para imputar como propio lo sucedido, lo que en la praxis acaece cuando una persona competente se organiza de forma tal, que lo organizado tenga objetivamente un sentido delictivo. Para ello, tanto las intenciones (dolo) como los conocimientos (saber) de quien realiza la aportación son irrelevantes. "Quien realiza algo estereotipado socialmente como adecuado no responde, y ello con independencia de lo que piense y conozca". ${ }^{32} 33$ Situación exactamente contraria a la del individuo que se adapta a un plan delictivo, otorgando motivos para que el hecho típico le sea imputable. Finalmente, agrega una frase que cierto sector doctrinario tilda de "incoherente" ", al afirmar que califica el sentido de un comportamiento no solamente la configuración del mismo, sino también el contexto en que se enmarca (por lo que puede que un comportamiento marcadamente delictivo sea socialmente tildado de adecuado). Para exponer ambos puntos de vista, así como el nuestro, nos permitiremos dar un ejemplo del que se valen ambas teorías para

\footnotetext{
${ }^{27}$ Jakobs, Günther: La imputación objetiva en Derecho Penal, $1^{\text {a }}$ edición, Editorial Civitas, Madrid, 1996, p. 164.

${ }^{28}$ Si bien se estudiará más adelante, a modo de enunciación, para Jakobs la punibilidad atiende al contexto en el que se enmarca el comportamiento del "hombre de atrás". Es decir, para el caso en concreto, si es que al ingresar al local, se percatara el cazador de una gresca y aun así procediere a colgar su escopeta (p.ej.).

${ }^{29}$ Rudolphi, Hans-Joachim: Causalidad e imputación objetiva, Universidad Externado de Colombia, Colección de Estudios No 13, 1998, p. 52.

${ }^{30}$ En oposición a autores como Frank, quien la construye a partir de los presupuestos conceptuales de la inducción.

${ }^{31}$ Jakobs, Günther: La imputación objetiva... (nota 27), p. 150.

32 Ibid., p. 163.

33 Es decir, la exclusión de punibilidad no depende de la convergencia de imprudencia o dolo en el "hombre de atrás". La configuración del mundo en el que se interviene no se modifica por actuar aquél de forma dolosa, sino que sólo varía la consciencia de estar realizando ello (saber).

34 [así] Piña Rochefort, Juan Ignacio: Rol social y sistema de imputación. Una aproximación sociológica a la función del Derecho Penal, $1^{\text {a }}$ edición, J. M. Bosch Editor, España, 2005, p. 360.
} 
fundamentar su postura: delante de una tienda de jardinería, la cual se encuentra funcionando conforme a su horario habitual, se está desarrollando una violenta pelea. De pronto, ingresa al local un sujeto manifiestamente menoscabado (herido), quien solicita la venta de una pala. Para Jakobs, atendiendo al contexto la venta sería evidentemente punible. Para Piña (quien indudablemente sigue en este punto a Lesch), como el rol delimita los contornos de toda imputación, el vendedor no respondería penalmente, ya que no posee el deber de emplear los conocimientos especiales con que cuenta para así subsanar un determinado curso de acontecimientos (conforme a la estructuración social la función de controlar el desempeño ajeno le corresponde a otros -carabineros p.ej.-, no al vendedor). ${ }^{35}$ Es decir, hace suya la primera parte de Jakobs analizada (el que sabe no tiene el deber de utilizar sus conocimientos, porque éstos son absolutamente irrelevantes). Asimismo, para Piña, los conocimientos pertenecen al rol en que se desempeña el individuo, siendo ambos indisolubles. Por tanto, cuando se sabe sin deber saber como en el caso de quien vende la pala, quien no debería menos que representarse (saber) que de celebrar la compraventa se producirá la perpetración de un delito-, no se es responsable. ${ }^{36}$ Empero, reconoce que su argumentación tiene como límite el delito común (de infracción de deber) de omisión del deber de socorro, el que no es más que la manifestación de una obligación institucional común a todas las personas: la solidaridad. En síntesis, para Piña, los conocimientos ajenos al rol en que se actúa no pueden fundar la responsabilidad del autor (negación de su responsabilidad por falta de competencia). ${ }^{37}$ Nuestra opinión es totalmente disidente. Ello porque, si bien concordamos con el principio de irresponsabilidad por hechos de terceros, así como con el de exclusiva responsabilidad sobre hechos propios, nos parece que del hecho de vivir en comunidad se deriva una serie de exigencias que hacen posible nuestra razonable convivencia. En razón de lo precedente, concordamos con la teoría que inmediatamente expondremos.

(e) Atendiendo a lo implausible de una prohibición de regreso genérica como la propuesta por Piña para decidir sobre la punición del "hombre de atrás", hay que situarse en el límite del principio de confianza ${ }^{38}$, esto es, cuando se puede confiar en que otros no cometerán delitos dolosos. Como consecuencia de dicha confianza se venden palas en las jardinerías. Sin lugar a dudas limita también con los riesgos permitidos, ya que un potencial peligro se tolera en atención a las ventajas superiores que otorga la realización de dicha conducta (en el caso de la jardinería: el normal funcionamiento del comercio). Ahora, "lo correcto es que el principio de confianza no puede regir ya cuando una conducta fomenta la perceptible

\footnotetext{
${ }^{35}$ Por más que tenga un unívoco sentido de cooperación delictiva.

36 Para el autor, la inimputabilidad que genera el actuar conforme a las prescripciones del rol encuentra su límite en la instrumentalización de éste (rol).

${ }^{37}$ Ello, según Piña, porque no se puede exigir que cada vez que el vendedor de la jardinería realice una venta deba averiguar sobre los posibles usos que le quieran dar los adquirentes. Por tanto, si no se exige indagar, con menor razón se exige saber, y por ende, si no se exige saber, no se puede hacer responsable a alguien por el simple hecho de que sabe algo (!). Es decir, iguala la venta de una pala a la de un cepillo de dientes.

38 [así también] Martínez Escamilla, Margarita: La imputación objetiva... (nota 6), p. 350.
} 
inclinación o propensión al hecho delictivo de un potencial autor doloso"39, por lo que no es la admisión de una confianza absoluta, sino que es un poder confiar de carácter normativo. Es decir, Roxin ${ }^{40}$ llega a una solución similar (no idéntica) a la de Jakobs ${ }^{41}$, ya que al utilizar como criterio de delimitación del riesgo permitido el fomento o favorecimiento de la perceptible inclinación al hecho delictivo y Jakobs un criterio según el cual el hecho del "hombre de atrás" es imputable como comisión imprudente en caso de que la acción dolosa del "hombre de adelante" tenga un sentido objetivo que sólo puede estar al servicio de la realización de un delito $^{42}{ }^{-43}$, ambos atienden a una previsibilidad objetiva del comportamiento doloso para determinar cuando estamos o no ante un riesgo permitido, es decir, negando las dos teorías que la conducta conforme a rol garantiza que el individuo no se ha extralimitado del riesgo permitido. ${ }^{44}$

Se opone a esta conclusión Reyes Alvarado, quien a nuestro juicio de modo erróneo argumenta que quienes cimentan la prohibición de regreso en la previsibilidad excluyen de imputación a alter cuando de manera imprudente permite que ego arbitrariamente se valga de su conducta y perpetre un delito doloso, atendiendo a la imprevisibilidad del actuar del tercero. ${ }^{45}$ Para ello aduce que estadísticamente existen muchas hipótesis de resultados que pueden considerarse como previsibles, mas para los cuales sería absurdo que dicha previsibilidad deviniera en responsabilidad. Para esto se vale del caso de los accidentes que se producen en automóviles, donde la previsibilidad de su

\footnotetext{
${ }^{39}$ Roxin, Claus: Derecho Penal... (nota 26), p. 1.007.

${ }^{40}$ Es menester señalar que el autor tiene para su criterio de propensión al hecho dos premisas fundamentales: (a) que la primera acción por sí misma no pueda ser interpretada como intolerablemente peligrosa; (b) que su contenido sólo puede descubrirse según las intenciones reconocibles (según el contexto) del potencial autor doloso posterior [idea obtenida en:] Piña, Rochefort, Juan Ignacio: Rol socialy sistema de imputación... (nota 34). p. 357.

41 La disimilitud consiste en que para Roxin la relación delictiva de sentido depende del conocimiento que tenga el partícipe de la finalidad del autor, así como de su intención interna (desvalor de intención). En cambio, para Jakobs la subjetividad carece de toda trascendencia. A su vez, porque para el primero el tipo no se relaciona con el quebrantamiento de un rol, sino que con la adecuación de la conducta.

${ }^{42}$ Es importante destacar lo impreciso de esta aseveración, porque no existen tales acciones, ya que incluso la adquisición de elementos tales como armas de fuego puede servir para situaciones consideradas como "heroicas", tales como la legítima defensa de terceros. Así también Piña, Rochefort, Juan Ignacio: Rol social y sistema de imputación... (nota 34). p. 359 y Roxin, Claus: Derecho Penal... (nota 26), p. 1.008 .

${ }^{43}$ [así mismo] Von Hirsch, Andrew y Wohlers, Wolfgang: “Teoría del bien jurídico y estructura del delito. Sobre los criterios de una imputación justa”, en Hefendehl, Roland (Ed.): La Teoría del Bien Jurídico, Marcial Pons Ediciones Jurídicas y Sociales S.A., Madrid, 2007, p. 295. Ello porque para los autores atendiendo a la ambivalencia general de toda conducta, "sólo se puede utilizar como criterio la función que corresponde a una conducta conforme a su fin".

${ }^{44}$ Por lo que el propietario de dicha jardinería usualmente no responde por las lesiones que uno de sus clientes pueda ocasionar a otro individuo. Sólo es responsable penalmente cuando del análisis de la situación concreta se determina un indudable sentido delictivo.

45 [así lo establece en] Reyes Alvarado, Yesid: Imputación... (nota 15), p. 325.
} 
acaecimiento no deriva en la responsabilidad de sus fabricantes. Nos parece que este ejemplo ${ }^{46}$ es equívoco, porque si bien es previsible el acontecer dañoso, se permite su utilización porque los beneficios que producen son mayores que los perjuicios (así lo establecía hace más de un siglo atrás Savigny en el caso de la locomotora, que con su desplazamiento generaba chispas que provocaban incendios en los campos de trigo), por lo que acá existe un límite "económico" a dicha previsibilidad, consistente en el beneficio general. A su vez, porque el fabricante efectivamente responde cuando entrega un producto que previsiblemente (lo que se analiza expost) carece de las medidas necesarias para que el desplazamiento sea seguro (si no, se le sancionaría de igual forma que en el caso Erdal o de aerosol para cueros -Lederspray-, Alemania, 1990).

En síntesis, cuando la acción del "hombre de atrás" tiene un unívoco sentido de cooperar con un delito, debe a éste hacérsele responsable, aun cuando su actuación se encuentre amparada por la cotidianeidad o incluso por su rol, ya que este último nos sirve no como un criterio infalible para la determinación de si el sujeto actuó o no conforme a las expectativas sociales (deber), sino que solamente como una ayuda para determinar el sentido de su conducta. ${ }^{47}$

\section{La prohibición de regreso, ¿límite a la posibilidad de sancionar como partícipe imprudente o a la autoría de un delito culposo?}

Si bien, en la praxis, por la asimilación de la pena del partícipe a la del autor dictaminada por el artículo 15 del C.P.Ch., en cuanto a la determinación de la pena, esta distinción puede devenir en inocua; es menester una toma de postura en este punto, ya que cada forma de intervención en un delito posee requisitos distintos para su punición. Por ello es de suyo importante exponer nuestra posición dentro de una dogmática totalmente dispersa.

Para una primera postura -a la cual adherimos-, la participación imprudente es punible en conformidad a las reglas generales del castigo de las formas de participación. Existe una segunda alternativa, intermedia, defendida por Mir Puig ${ }^{48}$, para quien son punibles las formas de participación equiparadas en pena a las de autoría (es decir, en el C.P.Ch., las hipótesis comprendidas en el 15 $\mathrm{N}^{\circ} 2$ y 3). Finalmente, hay una tercera alternativa, defendida por disímiles autores, tales como Reyes Alvarado ${ }^{49}$, Díaz y García Conlledo ${ }^{50}$ y Muñoz Conde ${ }^{51}$, quienes sostienen que la participación imprudente es impune.

\footnotetext{
46 [ubicado en:] Reyes Alvarado, Yesid: Imputación... (nota 15), p. 326.

47 Así tampoco en los casos en que la conducta no es estereotipada como cotidiana se deriva sin más la consecución de una conducta imputable.

48 [así:] Mir Puig, Santiago: Derecho Penal Parte General, 5a edición, Editorial Reppertor, Barcelona, 1998, p. 368.

${ }^{49}$ Reyes Alvarado, Yesid: Imputación... (nota 15), p. 318.
} 
Participar es intervenir en un hecho ajeno, es decir, el hecho del partícipe depende del hecho del autor (accesoriedad), siendo siempre una extensión de la punibilidad, razón por la cual la última teoría esbozada argumenta que dichos preceptos deben de interpretarse restrictivamente, así como por su menor gravedad y su carácter de excepcional. Empero estos argumentos, que podríamos tildar de político-criminales nos parecen absolutamente objetables, ya que como señala Rudolphi "regala impunidad sin que el beneficiario se lo merezca, ya que en principio ha infringido una norma penal" ${ }^{52}$, es decir, hace homogéneas una conducta socialmente adecuada con una conducta que no lo es (clara alusión al pensamiento de Frank). ${ }^{53}$ Asimismo, es muy prudente la objeción que Roxin ${ }^{54}$ le realiza a Wehrle de que no se puede derivar que la "complicidad" culposa quede impune, arguyendo el exiguo merecimiento de pena de la complicidad (dolosa) en comparación con la autoría dolosa, "pues las razones que en los hechos dolosos apoyan la división de las formas de participación en autoría, instigación y complicidad, no tienen significación para las formas culposas de conducta en razón del concepto unitario de autor" ${ }^{\prime 55}$ (para la cual es autor solamente el individuo en quien concurren todos los elementos de la descripción típica).

En razón de todo lo precedente concordamos con autores como Jakobs, quien considera punible la participación imprudente en un hecho doloso.

Ahora, basándonos en nuestra regulación legal, que a diferencia del StGB -en el cual sólo se castiga la participación dolosa- ${ }^{56}$, para la inducción imprudente no se contiene la exclusión del castigo, ya que no se exige que alter induzca

50 Díaz y García Conlledo, Miguel: “Autoría y participación”, en Revista de Estudios de la Justicia (REJ), No 10, año 2008, p. 29.

51 Muñoz Conde, Francisco y García Arán, Mercedes: Derecho Penal Parte General. $7^{a}$ edición, Editorial Tirant lo Blanch, Valencia, 2007, p. 230.

52 [citado por] Feijoo, Sánchez, Bernardo: Imputación Objetiva... (nota 17), p. 359.

53 Para demostrar lo aberrante del entendimiento de una participación imprudente impune piénsese en el caso "Alcalá 20" (TS, 17 de junio de 1995): en una discoteca madrileña murieron más de ochenta personas y cientos resultaron lesionados producto de un incendio de origen doloso. Empero, si bien lo anterior, dicho establecimiento carecía de las medidas de prevención para incendios necesarias y establecidas por los preceptos administrativos. Si siguiéramos a los autores que profieren que la participación imprudente es impune, la responsabilidad dolosa del autor debería haber desencadenado la impunidad de los titulares del establecimiento -quienes actuaron sólo de manera imprudente-. [ejemplo obtenido en] Gimbernat, Enrique: "Omisión impropia e incremento del riesgo en el Derecho Penal de empresa”, en Díaz Aranda, Enrique (Ed.): Problemas fundamentales de Politica Criminal y Derecho Penal, Universidad Nacional Autónoma de México, 2002, pp. 55-59.

54 [citado por] Rudolphi, Hans-Joachim: Causalidad... (nota 29), p. 52.

55 Ibid.

56 El cual dictamina: \26. Instigación (inducción a delinquir) (...) Instigador es quien haya determinado dolosamente a otro para la comisión de un hecho antijurídico. \27. Complicidad: (1) Como cómplice se castigará a quien haya prestado dolosamente ayuda a otro para la comisión de un hecho doloso antijurídico. 
dolosamente a ego a cometer el delito, pudiendo por tanto ser suficiente que el inductor conozca el contexto peligroso en que se despliega la conducta por parte del autor ejecutor (imprudencia). ${ }^{57}$ En razón de ello, el argumento dogmático de exclusión de la imputación del "hombre de atrás" por imposibilidad normativa en la inducción imprudente en un delito doloso es completamente desechable.

A su vez, en la complicidad, la argumentación puede resultar más compleja, ya que es cómplice quien dolosamente presta ayuda a otro para que éste dolosamente efectúe un delito. ${ }^{58}$ Es decir, el C.P.Ch. excluye la imputación del "hombre de atrás" que coopera imprudentemente a la ejecución del hecho. Nos parece muy pertinente el argumento de Frisch para esclarecer este embrollo. Éste, para casos en los cuales el legislador pune sólo el favorecimiento doloso del comportamiento delictivo de terceros responsables, asume como punto de partida que no es posible, sin incurrir en excesos interpretativos, calificar la conducta como autoría imprudente, y menos calificarla de impune ${ }^{59}$, "ello porque la falta de tales preceptos puede explicarse en virtud de una menor prefiguración y una mayor extensión de la conducta de autoría en los delitos imprudentes". ${ }^{60}$ En razón de lo precedente, la falta de preceptos sobre la complicidad imprudente no puede otorgar una orientación concluyente, sino que ésta debe ser producto exclusivo del "análisis de la propia extensión de los tipos imprudentes en cuestión". ${ }^{61}$ Es decir, para el caso de la complicidad la solución no se encuentra en el ámbito de la participación, sino en la extensión de las conductas de autoría en los delitos imprudentes (en el C.P.Ch. fundamentalmente los del título XVIII, es decir crímenes y simples delitos contra las personas).

\section{Delimitación de la esfera de aplicación de la teoría}

Se han postulados cinco grandes grupos de limitaciones para la aplicación de la prohibición de regreso: (a) por consideraciones de irrelevancia penal; (b) por aplicación de las reglas generales de la imputación objetiva; (c) conforme al sentido del comportamiento; (d) supuestos en los que existen posiciones de garantía, y (e) supuestos de autoría mediata.

(a) Irrelevancia penal (Anarte Borrallo): para él la imputación imprudente del "hombre de atrás" va "demasiado lejos", "imposibilitando diferencias valorativas entre las diversas posibilidades, por lo que, en última instancia, resulta incorrecta

\footnotetext{
${ }^{57}$ Artículo concomitante: $15 \mathrm{~N}^{\circ} 2$ C.P.Ch.

58 Artículo concomitante: 16 C.P.Ch.

59 Para el autor, sólo es pertinente deducir de ello que la conducta ahí indicada no puede ser calificada de autoría dolosa.

${ }^{60}$ Frisch, Wolfgang: Comportamiento típico e imputación del resultado, Editorial Marcial Pons, Madrid, 2004, p. 255.

${ }^{61}$ Ibid.
} 
en sus consecuencias". ${ }^{2}$ Señala a su vez, que el derecho debe comprender la singularidad de una expectativa razonable de que terceros no se aprovecharán favorablemente de las circunstancias creadas por la imprudencia del "hombre de atrás" para la comisión de un hecho punible. Ello lo traduce en que, si bien se infringe un deber de cuidado por parte del hombre de atrás, dicha transgresión no se considera como especialmente grave, lo que respecto al resultado de afección a un bien jurídico que pudiere acaecer impediría castigarlo como delito, "pudiendo sólo acudirse a la falta de imprudencia". ${ }^{63}$ Empero, profundiza el autor, la solución más idónea, sería persistir en que hay una falta de diligencia, "pero que ésta (sic) no llega a tener relevancia penal, porque sólo es una imprudencia civil [...] que podría dar lugar a una responsabilidad civil". ${ }^{64}$

Nos parece que el planteamiento de este autor es inidóneo. Para demostrar ello creemos bastante pertinente criticar la solución que otorga aludiendo a la clásica sentencia alemana ${ }^{65}$ de que él mismo se vale: Alter deja un abrigo en el guardarropía de un teatro, conteniendo dicha prenda en uno de sus bolsillos un revolver cargado. Uno de los trabajadores del teatro lo encuentra y aprieta el gatillo creyendo que estaba descargado, ocasionándole la muerte a un tercero. El hecho de poseer este tipo de artefactos y "custodiarlos de manera descuidada, de modo que otro pueda tener acceso a ellos, ya vincula al sujeto con las consecuencias delictivas" ${ }^{\$ 6}$, por lo que la expectativa de que los encargados del guardarropía no hurgarán en los bolsillos de las prendas, y menos aun, que si lo hicieren comenzaren a "divertirse" con el revólver, se desmonta fácilmente con el deber de garante que posee el dueño del abrigo, de no disponibilidad del revólver respecto de terceros, respondiendo de las consecuencias delictivas asociadas a la infracción de dicho deber.

(b) Por aplicación de las reglas generales de la imputación objetiva (Reyes) ${ }^{67}$ : para su mejor comprensión estudiaremos cada uno de los casos en que se aduce su prescindibilidad.

(b.1) Conductas posteriores erradas de la víctima (también denominadas supuestos de confluencia de conductas $^{68}$ ): hay casos en los cuales la conducta imprudente o incluso dolosa del "hombre de atrás", siendo causa necesaria para la producción del resultado final, no es suficiente para su consecución. Estas son las situaciones en que la afección se produce por una conducta descuidada de la

\footnotetext{
62 Anarte Borrallo, Enrique: Causalidad e imputación objetiva en el Derecho Penal, $1^{\mathrm{a}}$ edición, Editorial Bartolomé de las Casas, Huelva, 2002, p. 86.

${ }^{63}$ Ibid.

${ }^{64}$ Ibid.

${ }^{65}$ Publicada en: RGSt, 31, pp. 91 ss.

${ }^{66}$ Jakobs, Günther: La imputación... (nota 27), p. 161.

${ }^{67}$ [Clasificación propuesta en] Reyes Alvarado, Yesid: Imputación ... (nota 15), pp. 338 ss.

68 Cancio Meliá, Manuel: "La exclusión de la tipicidad por la responsabilidad de la víctima (imputación a la víctima)", en del mismo: Estudios de la teoría de la imputación objetiva, Editorial Ad Hoc S.R.L., Buenos Aires, 1998, p. 139.
} 
propia víctima, es decir que si ésta se hubiese desempeñado de forma esperable el resultado lesivo no hubiere acaecido (v. gr. alter es arrollado por el vehículo de ego, sufriendo el primero una lesión que con un tratamiento oportuno no revestiría caracteres de fatalidad, mas alter se niega a que le sean practicados dichos cuidados, produciéndose como resultado de dicho rechazo la muerte de alter). Es una solución pacífica en la doctrina negar la imputación de quien aporta la primera condición en aquellas situaciones en que el resultado es consecuencia de un error grave de la víctima, entendiendo ello como contrario a leve, distinción que atiende al grado de probabilidad de que el resultado final hubiere podido evitarse. Asimismo, deja de ser imputable el resultado cuando la víctima actúa de modo que el resultado lesivo se produzca.

Ahora bien, agregamos éste a la clasificación, ya que autores tales como Reyes $^{69}$ consideran que los casos de conductas posteriores erradas de la víctima deben resolverse aplicando solamente la teoría de la imputación objetiva, "sin necesidad de recurrir a la creación de mecanismos ad hoc para la solución de los respectivos problemas". ${ }^{70}$ Para ello, él determina cuándo debe o no haber imputación del primer autor, mediante el análisis de la creación de riesgos jurídicamente desaprobados que se generó con la conducta del primero. ${ }^{71}$

Nos parece que esta apreciación no es tan correcta. Concordamos en cuanto al sujeto que se imputa, mas no en el criterio a través del cual se lo hace. Lo primero es muy sencillo, ya que así lo dice el sinalagma, el correlato de la libertad es la responsabilidad, es decir, es la víctima quien debe asumir de modo preferente los daños que se derivan de su conducta errada. Situación contraria derivaría en "privar al titular de su libertad de organización, e imponer a los demás un deber de tutela que, al no estar formulado de modo expreso, no existe". ${ }^{72}$ En cambio, lo segundo - prescindir de la prohibición de regreso- nos parece a lo menos discutible. Utilizaremos un ejemplo para exponer nuestras disensiones. Alter

\footnotetext{
${ }^{69}$ Reyes Alvarado, Yesid: Imputación... (nota 15), p 38.

${ }^{70}$ Ibid.

71 Un diagnóstico similar respecto a la prohibición de regreso, pero en el ámbito de la responsabilidad civil extracontractual realiza el profesor Enrique Barros, quien la considera una "terminología discutible pero generalizada", en la que para él basta aplicar el criterio de la causa adecuada para concluir en cuáles casos el "hombre de atrás" puede ser hecho responsable de los "nuevos daños" [en] Barros, Enrique: Tratado de responsabilidad extracontractual, Editorial Jurídica de Chile, Santiago, 2006, p. 412.

Adecuada es aquella condición que generalmente es apropiada para producir un resultado determinado, excluyéndose por tanto los acontecimientos causales con los que no podía contar un observador ajeno razonable en el tiempo de la acción. El problema de esta teoría es que cuando dicho observador puede prever acontecimientos extraordinarios lesivos, que razonablemente aparecen como comportamientos adecuados, hace que la teoría requiera elementos de los que carece. Como consecuencia de ello no posee aplicación generalizada, siendo por nosotros desechada.

${ }^{72}$ Cancio Meliá, Manuel: "La exclusión de la tipicidad..." (nota 68), pp. 121-122.
} 
guarda en un recipiente de gaseosa un líquido venenoso, el cual, por necesidades del producto guarda en el refrigerador. Es preciso señalar que alter vive solo. Un día, ego ingresa de forma no autorizada a la vivienda e ingiere el veneno pensando que era Coca Cola, sufriendo una intoxicación. Aunque ambos concordamos que alter no es penalmente responsable, nos parece que prescindir de los criterios normativos que nos entrega la prohibición de regreso no es beneficioso, porque si bien, admito la evidente existencia del vínculo causal, así como la creación de un riesgo inadecuado, ambos son criterios demasiado arraigados a datos naturalistas, obviando por tanto lo fundamental, es decir la correspondiente ausencia de una expresión de sentido de la persona competente que se organiza de forma tal para alcanzar las consecuencias delictivas (previsibilidad). A mayor abundancia, determinar que el riesgo desaprobado que con su conducta creó alter no se realizó en el resultado intoxicación, sino que fue consecuencia de la conducta errada de ego, mediante la determinación de si el resultado se explica o no por la conducta reprochable del autor, creemos que no es tan idóneo, porque pueden acaecer situaciones en las que el riesgo jurídicamente desaprobado que alter generó con su conducta se realiza en el resultado penalmente relevante, empero, escapa de la previsibilidad objetiva.

A nuestro juicio la solución idónea se cimenta a partir del principio de confianza; ello porque el "hombre de atrás" puede confiar en que la víctima se comporte conforme a deber, con la excepción de que existan indicios especiales que le hagan creer lo contrario, es decir, que deba contar con dicha actuación contraria a deber de la víctima (previsibilidad), siéndole imputable el resultado final -por la realización del peligro por él creado- (opera la prohibición de regreso cuando al momento de efectuarse el comportamiento era factible confiar).

(b.2) Conductas posteriores erradas de un tercero (dolosas o imprudentes): al igual que lo explicado anteriormente, se trata de situaciones en las que se elimina la imputación objetiva del primer causante sobre el resultado final. Un ejemplo claro de ello es si alter colisiona a ego provocándole lesiones que no revisten el carácter de mortales, mas ego muere producto de una negligencia médica en el tratamiento de las mismas. Es menester precisar que ello no significa siempre impunidad para el primero, por razones análogas a las ya expuestas en el caso del cazador y la taberna.

Reyes rechaza la aplicación de la teoría de la imputación objetiva, utilizando también aquí el criterio de los riesgos desaprobados previos a la realización del resultado penalmente relevante mediante previa indagación de cuál de las conductas reprochables es la que permite explicar el daño.

En este caso, siguiendo a Rudolphi, nos oponemos a la exclusión de la aplicación de la teoría de la prohibición de regreso cuando hay un resultado antijurídico causado dolosamente por un tercero responsable, quien se vale de una aportación no dolosa del "hombre de atrás", que agrega una condición para el resultado antijurídico de dicho tercero, ya que, siguiendo al mencionado, lo 
decisivo es si el "hombre de atrás" con su conducta imprudente ha creado el peligro de producir el resultado mediante un hecho doloso ajeno, y si este hecho doloso se ha concretado en la producción del resultado. Hasta aquí no hay diferencias con el autor colombiano, mas Rudolphi agrega como criterios complementarios de lo señalado que lo determinante es "si y con qué alcance el primer autor estaba obligado, de acuerdo con el correspondiente tipo penal culposo que está en consideración, a omitir acciones que facilitaran o favorecieran un hecho penal doloso ajeno" "73, o sea, en la práctica analiza las exigencias comprendidas en las figuras penales especiales, dependiendo el castigo del "hombre de atrás" de consideraciones diferenciadas (no existe una "ley" general de aplicación de la teoría de la prohibición de regreso o de atribución de responsabilidad). Por ello, aduce el autor que "sólo puede contar con hechos punibles de terceros si para ello se dan puntos de referencia concretos" ${ }^{\text {"74 }}$, lo que no es más que cercenar de la esfera de punición las conductas que no pueden entenderse objetivamente como favorecimiento de un hecho delictivo ajeno, determinándose ello según el acaecimiento o no de los elementos objetivos del tipo correspondiente (principio de confianza).

Asimismo, también nos parece insuficiente el criterio de Reyes para los casos de una conducta ulterior imprudente de un tercero, ya que existen riesgos en los cuales el acaecimiento de una acción culposa por un tercero es más que posible (siendo por tanto el resultado final manifestación de dicho riesgo).

(c) Conforme al sentido del comportamiento (Jakobs): para incoar es fundamental para comprender el argumento del autor precisar que toda conducta puede ser instrumentalizada por un tercero. Ahora bien, mediante este criterio se busca determinar cuándo una organización se encuentra configurada de forma tal, que tenga sentido para alcanzar consecuencias delictivas, para así determinar cuándo se participa en las consecuencias delictivas de dicho contexto de acción. Para ello forma cuatro grupos de casos, en los cuales en dos concurre responsabilidad en el "hombre de atrás". Estos últimos son:

(c.1) Casos en los cuales lo común entre el "hombre de atrás" y el autor viene determinado por la configuración de la prestación, la que es per se peligrosa: A las mencionadas prestaciones les es inherente un uso ulterior potencialmente delictivo, razón por la cual generan una comunidad normativa con quien realiza la ejecución, es decir, con independencia del fin que persiga el "hombre de atrás" (no depende de sus circunstancias psíquicas) se pone en un nivel común con quien ejecuta la acción; ello gracias a su prestación, ya que "ha organizado la situación de tal modo que las consecuencias delictivas forman parte del sentido de su organización". ${ }^{75}$ Es menester precisar que en todo lo señalado para la prestación debe entenderse comprendida la omisión (v. gr. en el caso del cazador y la taberna

\footnotetext{
${ }^{73}$ Rudolphi, Hans-Joachim: Causalidad... (nota 29), p. 52.

${ }^{74}$ Ibid, p. 53.

${ }^{75}$ Jakobs, Günther: La imputación... (nota 27), p. 161.
} 
anteriormente explicado, se encuentra éste vinculado a las consecuencias delictivas de su imprudencia omisiva).

(c.2) Casos de inducción y complicidad: ello simplemente porque ambos configuran su prestación de modo tal que encuadre dentro de un contexto delictivo. Es atingente señalar que acá también se prescinde de lo subjetivamente perseguido, bastando que el sentido del comportamiento sea el favorecer un delito (aunque no haya previsto el comportamiento delictual posterior).

En cuanto a la complicidad, el sentido delictivo del comportamiento es más que evidente por el hecho de que el favorecimiento delictivo es ulterior a la concurrencia del principio de ejecución del ilícito por parte del autor.

A su vez, en cuanto al inductor, al ser este quien determina a otro a la comisión de un hecho, creando en aquél la idea delictiva, es más que manifiesta su configuración en un unívoco sentido de cooperación delictiva (el autor principal no está decidido a la realización del ilícito penal, sino hasta el acaecimiento de la incitación, momento en el cual "surge" el dolo en el autor principal).

(d) Supuestos en que existen posiciones de garantía (omisión impropia): concurriendo esta posición, se impone al sujeto no sólo la obligación de no dañar, sino que también se le constriñe a proteger activamente ámbitos ajenos ${ }^{76}$ (respecto solamente del beneficiario), es decir, es imposible que la conducta de quien facilita el nacimiento de un riesgo se fije como acción u omisión ${ }^{77}$, derivándose por tanto las mismas consecuencias cuando un padre le entrega a su bijo una pistola cargada que cuando la deja sobre la mesa del living al alcance de éste, ya que en ambos casos se le imputa el hecho realizado por el autor (en este caso el hijo).

Son deberes cuya inobservancia adquiere el matiz objetivo de una cooperación delictiva (no, por tanto, de una mera infracción a un deber general de solidaridad). Como consecuencia de ello, al que favorece la conducta delictiva de un tercero, siendo objetiva y subjetivamente posible para él su evitación -ya que si no dicha imposibilidad de cumplir derivaría en su exoneración de responsabilidad-, le es imputable, "incluso aunque el favorecimiento se haya producido antes de que el autor haya resuelto crear dicho riesgo". ${ }^{78}$

\footnotetext{
${ }^{76}$ V. gr. la enfermera no puede defenderse argumentando que actuaba simplemente como madre y no como profesional cuando deja de prestarle primeros auxilios a su hijo accidentado en un día de campo. [ejemplo obtenido en] Piña Rochefort, Juan Ignacio: Rol social y sistema de imputación... (nota 34), p 375.

77 Distinción desechada por Jakobs, quien pregona la uniformidad de la fundamentación y delimitación de mandatos y prohibiciones, ello porque las considera a ambas comprendidas dentro de la misma competencia por organización ("fundamento jurídico especial"). [así en] Jakobs, Günther: "La imputación penal de la acción y de la omisión", en del mismo Cuadernos de conferencias y artículos, $\mathrm{N}^{\circ} 12$, Universidad Externado de Colombia, 1996, pp. 59-70.

${ }^{78}$ Feijoo Sánchez, Bernardo: Imputación Objetiva... (nota 17), p. 407.
} 
(e) Supuestos de autoría mediata: es autor mediato quien tiene dominio sobre la realización del hecho descrito por el correspondiente tipo legal pero lo lleva a cabo a través de otro, al que utiliza como instrumento. La acción ejecutada por el instrumento es en la praxis una obra del "hombre de atrás", ya que éste determina el sí y el cómo de la realización típica.

En atención a lo precedente, pareciere diáfano que el "hombre de atrás" posee una unívoca intención delictiva, siendo por tanto absolutamente inaplicable la teoría de la prohibición de regreso. Empero, en concordancia con la ampliación al dolo propuesta por Jakobs ${ }^{79}$, es decir, donde nada se altera si en quien causa de manera mediata el resultado concurre dolo en vez de imprudencia (excepto en cuanto al saber), hay que considerar como deslinde de esta delimitación de la esfera de aplicación de la teoría el que el autor mediato doloso "no responde si la motivabilidad de su actuación no se halla vinculada para él mismo al acto directamente lesivo y los planes ajenos que toma como base no sólo pueden estar motivados como planes delictivos" ${ }^{\prime 80}$ (en la praxis quiere decir que el autor mediato debe ser quien provoque o haga mantener en el error al "sujeto de adelante", causando así su conducta imprudente).

\section{Prohibición de regreso: ¿una limitación normativa a la responsabilidad penal accesoria en la inducción?}

La participación supone siempre la existencia de un autor; ello ya que aquél contribuye al hecho de éste (el hecho del partícipe depende del hecho del autor). La autoría es siempre principal y por ende la participación, accesoria. Del análisis de las diversas figuras de la Parte Especial sólo se desprende el castigo del autor, por lo que la participación no es más que la extensión de la punibilidad señalada en la Parte General (artículos 14, 15, 16 y 64 I del C.P.Ch.). Ahora, dogmáticamente, se distingue una de otra, conforme a la teoría del dominio del hecho (Welsen), atendiendo a quién determina el sí y el cómo de la realización delictiva, siendo partícipe, por tanto, quien carece de tal control sobre la producción de la contingencia.

A su vez, este límite del ius puniendi opera en relación a dos aristas: (a) la accesoriedad cuantitativa (grado de desarrollo en el iter criminis) y (b) la accesoriedad cualitativa (elementos del modelo Liszt-Beling). Ello porque como este principio implica dependencia, es fundamental delimitar la extensión de ésta (hasta dónde se puede extender la punición, o en otras palabras, cuándo se puede aplicar la prohibición de regreso). Para la cuantitativa, existe participación desde la tentativa (y hasta la consumación). Para la cualitativa, exige que el hecho del autor sea típico y antijurídico (accesoriedad limitada).

\footnotetext{
${ }^{79}$ Expuesta en el punto 1.(e).

${ }^{80}$ Jakobs, Günther: Fundamentos... (nota 14), p. 167.
} 
Ahora, "quien participa en la fase previa no responde jurídico-penalmente por coproducir el hecho de otro, sino porque el hecho resultante también es el suyo propio" ", es decir, existe una razón para imputar como propio lo sucedido, atendiendo a que organiza un contexto con consecuencias objetivamente delictivas (ajustado a su finalidad, sólo se pueden enlazar consecutivos comportamientos delictivos), lo que no es más que un comportamiento suficiente para infringir el deber ser (aunque respondiendo cada uno sólo por su propio injusto).

En atención a todo lo señalado precedentemente, un comportamiento se puede calificar de accesorio cuando se pueda imputar al "hombre de atrás" la realización del tipo, es decir, cuando se puede concluir que el hecho a que otro al menos dio principio de ejecución, también es suyo. Situación totalmente contrapuesta a esto es la prohibición de regreso, por tanto, la respuesta al enunciado formulado en este acápite no puede sino más que ser afirmativa.

Para concluir el presente, es menester esbozar la disimilitud existente entre Roxin y Jakobs en cuanto a la accesoriedad, ya que no sólo difieren en que para el primero domina el hecho quien determina el sí y el cómo de su consecución y, para el segundo, concurre dicho dominio si es que se enmarca dentro del ámbito de responsabilidad de la persona acotado por la esfera de sus competencias; sino que también en cuanto a que para Jakobs la accesoriedad no está determinada por un conocer o un querer del "hombre de atrás", sino sólo de la configuración del comportamiento según el contexto en que se enfrasca, y en cambio para Roxin, ello atiende a los conocimientos que posee el "hombre de atrás" de los fines del autor.

\section{Casos en que es necesario impedir sucesivas responsabilidades "hacia atrás".}

Si el adulterio fuese punible, ¿habría que condenar al carpintero que hizo el lecho donde se consumó la relación extramarital?, o ¿habría que punir a los padres de Erzsebeth Bathory por el simple hecho de haberla concebido?, o de modo más genérico, en los casos en que el "hombre de atrás" y el de adelante no tienen nada en común, sino que, por el contrario, el segundo enlaza su conducta a un comportamiento socialmente adecuado y cotidiano del primero, desviándolo hacia un resultado final típico; o existiendo entre ambos algo en común, se limita esa relación a una prestación fungible, es decir, que se puede conseguir en muchos lugares, no conllevando ésta per se riesgo especial alguno, haciendo el autor inmediato un uso especial de dicha prestación inocua para perpetrar el hecho típico, no cabe sino preguntarse: ¿son dichos comportamientos suficientes para generar responsabilidad?.

\footnotetext{
${ }^{81}$ Jakobs, Günther: La imputación... (nota 27), p. 151.
} 
A nuestro juicio la respuesta es negativa, ya que, siguiendo a Jakobs, la conducta no tiene por sí misma sentido delictivo, es decir, ésta no depende de que el autor ejecute el delito. Por tanto, para que exista imputación, es decir mutación desde una conducta neutral a un ataque al bien jurídico se requiere de una relación delictiva de sentido. La razón no es otra que una desaprobación penal de todo riesgo creado sería una restricción insoportable a la libertad de acción. Empero, ¿podríamos determinar la impunidad del "hombre de atrás" atendiendo a la relación entre la conducta y el bien jurídico protegido por el tipo penal?

Si se está dispuesto a tolerar como adecuados el acaecimiento de lazos de imputación sinuosos, la teoría del bien jurídico nos puede servir de punto de fuga para la determinación de las sucesivas responsabilidades hacia atrás. Empero, nos parece que una fórmula como aquella deriva en restricciones injustificadas para la libertad de las personas.

\section{Prohibición de regreso y teoría del bien jurídico.}

Para nosotros, siguiendo a Amelung ${ }^{82}$, debe entenderse por bien jurídico a aquellos estados de cosas (juicios de valor) que han sido valorados positivamente mediante procedimientos legislativos democráticos. Lo precedente es correlato lógico de pertenecer a una sociedad plural y tolerante en la que lo relativo a lo axiológico no se encuentra delimitado, por lo que valoraciones suprapositivas, es decir, no sometidas al consenso del discurso, no pueden justificar límites a la autonomía.

En concomitancia con lo señalado, el legislador nos señala qué estados de cosas deben ser conservados, constituyendo ellos el fundamento y límite del Derecho Penal, exceptuando por ende de sanción penal aquellas conductas que en sí no se vinculan a un bien jurídico penalmente protegido (función crítica de la teoría).

Si se permiten nexos alambicados, casi cualquier conducta puede ser válidamente relacionada con un bien jurídico. En razón de lo precedente, es muy pertinente la pregunta que formulan Von Hirsch y Wohlers ${ }^{83}$ en cuanto si ¿está permitido reaccionar con una conminación penal frente a conductas relacionadas sólo (sic) indirectamente con un interés protegido en sí mismo legítimo?, lo que para nosotros sería preguntarnos si las consecuencias sobre algún estado de cosas considerado como valioso están vinculadas con la conducta del "hombre de atrás" y, por ende, si se le puede responsabilizar penalmente. Resulta evidente que no, ya que lo concluyente para calificar de legal o ilegal a una norma no es su vinculación con un bien jurídico, sino "la relación que guardan las conductas abarcadas por el

\footnotetext{
82 Amelung, Knut: "El concepto $<<$ Bien Jurídico $>>$ en la teoría de la protección penal de bienes jurídicos”, en: Hefendehl, Roland (ed.): La Teoría del Bien Jurídico. Marcial Pons, Ediciones Jurídicas y Sociales S.A., Madrid, 2007, pp. 228 ss.

${ }^{83}$ Von Hirsch, Andrew y Wohlers, Wolfgang: “Teoría del bien jurídico...” (nota 43), p. 287.
} 
tipo penal con este bien" ${ }^{84}$ (téngase en consideración que en el varias veces expuesto caso de la amante, la conducta de ésta puede vincularse ya con el bien jurídico vida).

La prohibición de regreso como ya latamente hemos precisado es un límite al principio de accesoriedad sobre conductas (inocuas en sî) que consisten en una aportación riesgosa (o incluso dolosa) previa en la que se apoya otro individuo para producir un resultado dañoso para el estado de cosas considerado como bueno. Primeramente, es fundamental precisar que la sola circunstancia de aportar una causa necesaria, pero a la vez insuficiente, para la realización de un detrimento a un bien jurídico por parte de un tercero que se sirve de ella, no es suficiente para imputar responsabilidad al "hombre de atrás". En segundo lugar, como a quien participa en la fase previa se le hace responder penalmente porque el hecho resultante es considerado como suyo propio, podríamos señalar como la primera utilidad del bien jurídico el ser quien determina la punibilidad de la conducta del "hombre de atrás", ya que cuando el autor da principio de ejecución a la conducta que busca menoscabar a un bien jurídico digno de protección penal es cuando es potencialmente punible el "hombre de atrás" (aun cuando la conducta desde el comienzo posee un significado objetivo de cooperación delictiva, sin necesidad de analizar la conducta del autor directo para fundamentar el desvalor de su conducta). Ahora, siguiendo la misma dinámica, el "hombre de atrás" es punible cuando el fin de su conducta sólo puede entenderse mediante la ulterior conducta atentatoria de un bien jurídico, es decir el bien jurídico nos entregaría el elemento interpretativo necesario para determinar el contexto en el que se ejecuta la acción.

No obstante lo precedente, nos parece que la teoría del bien jurídico no posee mayor utilidad para determinar si la conducta mediata causante del resultado conlleva o no responsabilidad, por no aportar nada distinto a lo ya estudiado.

Asimismo, creemos que carece omnímodamente de relevancia la teoría del bien jurídico para la prohibición de regreso desde el prisma de las clases de tipos penales. Ello como consecuencia de que para todos aquellos tipos encasillados en la clase que atiende a su relación con el bien jurídico (delitos de lesión y de peligro) la teoría de la prohibición de regreso es aplicable. Para los tipos que requieren la lesión de un bien jurídico protegido es diáfano. Para los delitos de peligro, nos parece muy ilustrativo el siguiente ejemplo: alter y ego beben alcohol en un bar, estando el primero en manifiesto estado de ebriedad. Ego mantiene durante toda la velada diversos bienes materiales de su propiedad sobre la mesa, dentro de los cuales se encuentran las llaves de su vehículo. Durante el transcurso de la tertulia ego se levanta de la mesa para dirigirse al baño, situación que aprovecha alter para sustraer las llaves y proceder a conducir el vehículo (infringiendo la ley 19.495).

A su vez, ello se ve complementado porque no es privativo de dicha clase de tipos la aplicación de la prohibición de regreso, ya que para la clasificación

\footnotetext{
${ }^{84}$ Ibid.
} 
según las modalidades de su acción, así como para la que atiende a los sujetos también es aplicable. ${ }^{85}$

\section{Principio de confianza}

La conexión entre la prohibición de regreso con el principio de confianza es manifiesta, ya que mediante ambos se busca discernir si quien realiza una acción en el mundo -siendo ella de las que entran en contacto con comportamientos de otras personas- debe tener un determinado [deber de] cuidado con respecto a conductas potenciales de estos terceros.

En un mundo en que los contactos anónimos acaecen permanentemente, el confiar en que los otros se comporten conforme al cuidado debido es indispensable para que alter organice su mundo, ya que sabe lo que puede esperar de ego. Lo anterior es evidente pero, ¿cuándo alter puede contar con un determinado comportamiento de ego?

Para Piña, a quien procede en conformidad a su rol no se le puede hacer responsable por el hecho de que otros se aprovechen de su comportamiento, "aun cuando dicha utilización fuere previsible" (no es una confianza psíquica, sino una esfera en la que se está permitido confiar). Es correlato lógico de lo anterior que la producción de determinados riesgos no deviene necesariamente en imputabilidad por conducta imprudente. Para el mencionado autor, el único límite al principio de confianza (donde no basta confiar en que el resto se comportará conforme a su rol) es cuando se sabe algo que se tiene el deber de saber, así como la obligación de utilizar dicho saber (posición de garante del "hombre de atrás"). Sólo ahí no se puede seguir confiando.

Nuevamente disentimos con el profesor Piña, ya que creemos que los conocimientos especiales hacen que desaparezca el principio de confianza, por lo que no es necesario el acaecimiento de una posición de garante para que quien sepa algo que no tenga el deber de saber sea responsable por no tener en consideración la conducta ajena al momento de realizar la propia, cuya "única" motivación sea obtener un comportamiento directamente lesivo o dependa de los planes del ejecutor, los que sólo pueden estar motivados de manera delictiva (v. gr. el vendedor de la jardinería se comporta típicamente sin importar que su finalidad sea la contraprestación económica o pago a recibir, sean las lesiones).

Ahora, aun con las similitudes ya mencionadas, ambas teorías tienen una diferencia fundamental. Ello porque poseen esferas de aplicación diversas dentro de la teoría de la imputación objetiva. El principio de confianza atañe a los límites

\footnotetext{
85 Realizamos esta clasificación tripartita de las clases de tipos siguiendo a: Mir Puig, Santiago: Derecho Penal Parte General, $7^{a}$ edición, Editorial B de F, Buenos Aires, 2005, pp. 225-235.

${ }^{86}$ Piña Rochefort, Juan Ignacio: Rol social... (nota 34), p. 380.
} 
subjetivos (deberes de cuidado para comportamientos propios en consideración a potenciales conductas delictivas de otras personas que se sirvan de ellas). A su vez, la prohibición de regreso se vincula con el tipo objetivo (favorecimiento de la perceptible inclinación al hecho delictivo). Esta distinción en las vinculaciones de los tipos subjetivos y objetivos deriva en que el principio de confianza se utiliza como "límite de la imputación cuando un comportamiento reúne los requisitos objetivos de un tipo penal" ${ }^{\prime 7}$; ello en razón de que no se puede, ante tamaña evidencia, esperar que el menoscabo a un bien jurídico no ocurra (v. gr. en el caso de la reyerta callejera, si uno de los intervinientes golpeó e hirió a otro -delito de lesiones-).

\section{Síntesis}

1. No toda posibilitación culposa o incluso dolosa de un hecho doloso posterior es punible.

2. Quien da principio de ejecución a un hecho típico no sólo realiza su hecho propio, sino también el hecho de todos (empero respondiendo cada cual de su propio injusto).

3. En consideración a que toda conducta puede ser instrumentalizada por un tercero, el criterio fundamental para inhibir la aplicación de la prohibición de regreso es atender al sentido del comportamiento, es decir, si era objetivamente previsible el comportamiento doloso posterior (conducta tiene por sí misma sentido delictivo), atendiendo o no al desvalor de intención del "hombre de atrás" para determinar su punibilidad, según se sigue a Roxin o a Jakobs respectivamente.

4. Si bien, en conformidad a las reglas generales, la participación imprudente es punible, atendiendo a nuestra normativa, podemos constatar que la prohibición de regreso es un límite a la sanción como autor imprudente en el caso de complicidad, y como partícipe imprudente en el caso de la inducción, de ello como consecuencia de que el C.P.Ch., en su artículo $16^{\circ}$, al igual que el StGB, excluye la imprudencia.

5. Un comportamiento se puede calificar de accesorio cuando se puede imputar al "hombre de atrás" la realización del tipo, es decir, cuando se puede concluir que el hecho a que otro dio principio de ejecución, también es suyo. Situación totalmente contrapuesta a esto es la prohibición de regreso.

\footnotetext{
${ }^{87}$ Feijoo Sánchez, Bernardo: Imputación Objetiva ... (nota 17), p. 419.
} 
REJ - Revista de Estudios de la Justicia - No 13 - Año 2010

\section{BIBLIOGRAFÍA}

* AMELUNG, Knut: “El concepto 'Bien Jurídico' en la teoría de la protección penal de Bienes Jurídicos", en HEFENDEHL, Roland (Ed.): La Teoría del Bien Jurídico, Marcial Pons, Ediciones Jurídicas y Sociales S.A., Madrid, 2007.

* ANARTE Borrallo, Enrique: Causalidad e imputación objetiva en el Derecho Penal, $1^{\text {a }}$ edición, Editorial Bartolomé de las Casas, Huelva, 2002.

* BARROS, Enrique: Tratado de responsabilidad extracontractual, Editorial Jurídica de Chile, Santiago, 2006.

* CANCIO Meliá, Manuel: "La exclusión de la tipicidad por la responsabilidad de la víctima ('imputación a la víctima')", en Estudios de la teoría de la imputación objetiva, Editorial Ad Hoc S.R.L., Buenos Aires, 1998.

* DÍAZ y García Conlledo, Miguel: “Autoría y participación”, en Revista de Estudios de la Justicia (REJ), No 10, año 2008.

* FEIJOO Sánchez, Bernardo: Imputación Objetiva en Derecho Penal, Editora Jurídica Grijley E.I.R.L., Lima, 2002.

* FRISCH, Wolfgang: Comportamiento típico e imputación del resultado, Editorial Marcial Pons, Madrid, 2004.

"La imputación objetiva: estado de la cuestión", en Sobre el estado de la teoría del delito (Seminario de la Universitat Pompeu Fabra), $1^{a}$ edición, Civitas Ediciones, Madrid, 2000.

* GIMBERNAT, Enrique: "Omisión impropia e incremento del riesgo en el derecho penal de empresa", en DÍAZ Aranda, Enrique (Ed.): Problemas fundamentales de Politica Criminal y Derecho Penal, Universidad Nacional Autónoma de México, México, 2002.

* HRUSCHKA, Joachim: "Prohibición de regreso y concepto de inducción. Consecuencias", en Imputación y Derecho Penal. Estudios sobre la teoría de la imputación, Editorial Aranzadi S.A., Universidad de Navarra, 2005.

* JAKOBS, Günther: Fundamentos del Derecho Penal, Editorial Ad Hoc S.R.L., $1^{\text {a }}$ ed., Buenos Aires, 1996.

La imputación objetiva en Derecho Penal, $1^{\text {a }}$ edición, Editorial Civitas, Madrid, 1996.

"La imputación penal de la acción y de la omisión", en Cuadernos de conferencias y artículos $\mathrm{N}^{\circ} 12$, Universidad Externado de Colombia, 1996.

* KINDHÄUSER, Urs: “Cuestiones fundamentales de la coautoría”, en Revista Penal $\mathrm{N}^{\circ} 11$, enero 2003. [disponible en] www.cienciaspenales.net

* MARTÍNEZ Escamilla, Margarita: La imputación objetiva del resultado, $1^{\mathrm{a}}$ edición, Edersa Editoriales, Madrid, 1992.

* MIR Puig, Santiago: Derecho Penal Parte General, $5^{\text {a }}$ edición, Editorial Reppertor, Barcelona, 1998. 235.

Derecho Penal Parte General, $7^{\text {a }}$ edición, Editorial B de F, Buenos Aires, 2005, p. $225-$

* MUÑOZ Conde, Francisco y GARCíA Arán, Mercedes: Derecho Penal Parte General, $7^{\mathrm{a}}$ edición, Editorial Tirant lo Blanch, Valencia, 2007.

* NAUCKE, Wolfgang: "Sobre la prohibición de regreso en Derecho Penal", en NAUCKE, Otto y otros: La probibición de regreso en Derecho Penal, Colección de Estudios ${ }^{\circ}$ 11, Universidad Externado de Colombia, 1998.

* OTTO, Harro: "Diagnosis causal e imputación objetiva", en NAUCKE, Otto y otros: La probibición de regreso en Derecho Penal, Colección de Estudios $N^{\circ} 11$, Universidad Externado de Colombia, 1998.

* PIÑA Rochefort, Juan I.: Rol social y sistema de imputación. Una aproximación sociológica a la función del Derecho Penal, $1^{\text {a }}$ edición, J.M. Bosch Editor, Barcelona, 2005.

* REYES Alvarado, Yesid: Imputación objetiva, Editorial Temis S.A., Bogotá, 1994. 
Ananías - Prohibición de regreso

* ROBLES Planas, Ricardo: La participación en el delito: fundamentos y límites, Editorial Marcial Pons, Madrid, 2003.

* ROXIN, Claus: Derecho Penal Parte General, Tomo I: Fundamento de la teoría del delito, 2a edición, Editorial Civitas, Madrid, 1996.

* RUDOLPHI, Hans-Joachim: Causalidad e imputación objetiva, Colección de Estudios $\mathrm{N}^{\circ} 13$, Universidad Externado de Colombia, 1998.

* VON HIRSCH, Andrew y WOHLERS, Wolfgang: "Teoría del bien jurídico y estructura del delito. Sobre los criterios de una imputación justa", en HEFENDEHL, Roland (Ed.), La Teoría del Bien Jurídico, Editorial Marcial Pons, Ediciones Jurídicas y Sociales S.A., Madrid, 2007.

* Welsen, Hans: Derecho Penal Parte General, Roque de Palma Editor, Buenos Aires, 1956.

* ZAFFARONI, Eugenio: Derecho Penal Parte General, 2a edición, Editorial Ediar, Buenos Aires, 2002. 